\title{
A CULTURAL OVERVIEW ON THE CONCEPT OF INFINITY
}

\author{
PAOLO DI SIA \\ University of Padova, \\ School of Engineering and Department of Neuroscience, \\ Via Giustiniani 2, I-35128 Padova, Italy \\ E-mail address: paolo.disia@gmail.com
}

\begin{abstract}
The human being meets the idea of infinity very early, still a child, when he realises that he can go on counting using natural numbers until it is impossible to continue to count. The idea of infinity attracts and rejects, sometimes becomes an object of desire and sometimes of study and systematic research. Infinity is the testimony that intellect, even starting from experience, can overcome limits and boundaries. Our own limited experience on the Earth suggests the existence of something beyond it. Scientists, artists, philosophers, musicians, writers, mathematicians have often assumed towards this concept positions and opinions sensitively different. Infinity would be, by its etymology and nature, what escapes all possible classification and measurement, while mathematics tends to classify and measure every object it examines, and has been able to measure it. Infinity follows us from primary school until university, but often remains a misunderstood concept in the mathematical sense.
\end{abstract}

Key words: infinity, mathematics, culture, education, school, research, mystery.

\section{INTRODUCTION}

Tnfinity is a conquest of thought; it is the testimony that the intellect, even starIting from the experience, can overcome limits and boundaries. The human experience is finite and limited by its nature:

i) we can only touch objects that are close to us;

ii) we can only listen to sounds emitted from not too distant sources;

iii) the visual space is defined by the laws of perspective, in which points and lines remind us that vision is limited, confined within a horizon line that cannot be overcome.

On the other hand, it is perhaps just this world, this limited experience that suggests the existence of something beyond, of another world that is neither finite nor limited. It is precisely the presence of a limit that raises the question and requires the search for what is after, beyond (Di Sia, 2005; Di Sia ${ }^{a}, 2014 ; \mathrm{Di}$ Sia, 2015). 
The ancients had the pillars of Hercules as border of the world and wondered what was beyond. We passed them, but the questions about what is beyond our solar system, our galaxy, our universe, are of the same kind as those of the ancients (Figure 1).

We retrace some of the big routes that humanity has followed in the research and characterisation of the concept of infinity, from philosophy to mathematics and art. Schematisations are useful for identification of a starting point for more in-depth research of those tortuous ways that the history of thought has often travelled. Scientists, artists, philosophers, musicians, writers, mathematicians, even belonging to very similar cultural environments, often took towards this concept sensibly different positions.

We can identify two types of approach to infinity:

1. the classical approach: it considers infinity as something to be avoided, a loss of limit and measure, a labyrinth without exit, in which the harmony of determined and finished things is lost. This approach characterised the ancient Greek world, but also our time; the writer Jorge Luis Borges (1899 1986) in his work Otras Inquisiciones wrote: "There is a concept that corrupts and alters all the others. I do not speak of evil [...] I speak of the infinity" (Borges, 1976).

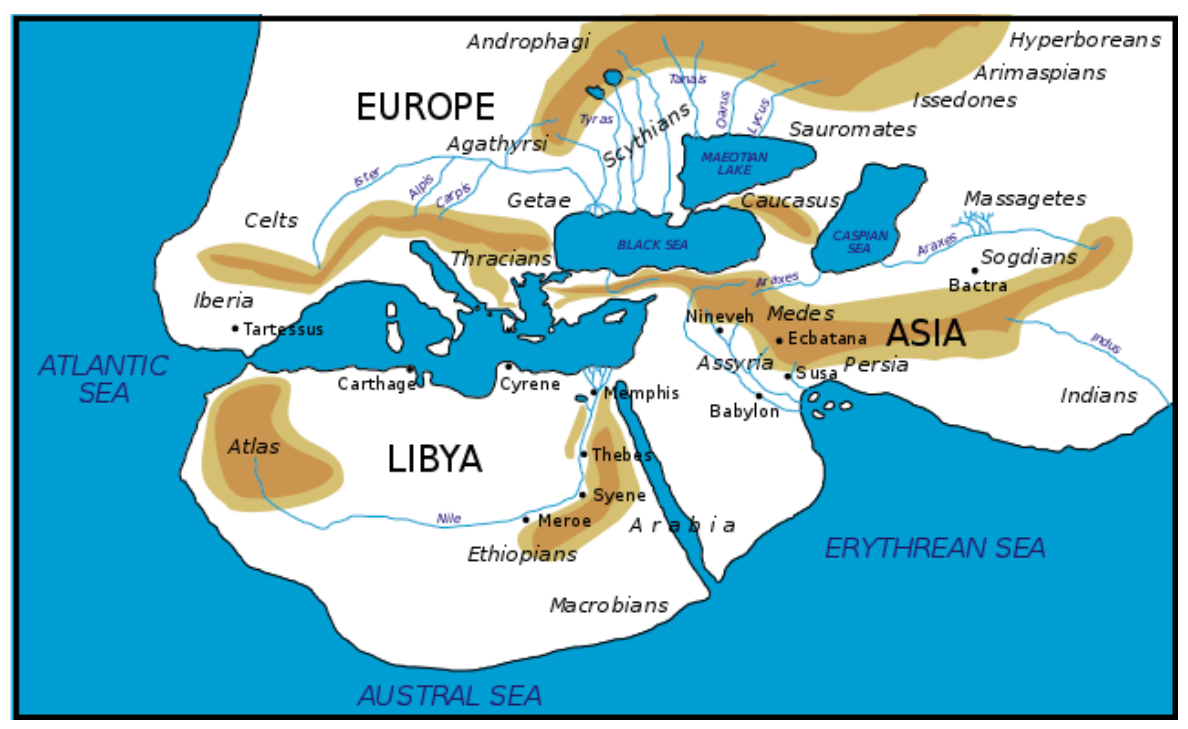

Figure 1. The world according to Herodotus $\left(5^{\text {th }}\right.$ century BC) $\left(\right.$ Online $\left.^{1}\right)$.

2) the romantic approach: it has the need to transcend the limits of everyday and sensitive experience to catch what is beyond. The romantic artist rebels against tradition, because it captures fantasy and creativity, prevents the spirit from venting the tension towards the infinity. This approach is characteristic not only of the Romantic period; in the $3^{\text {rd }}$ century, for example, the philosopher Plotinus created a structure of the universe with at the beginning the 
Journal of Education Culture and Society No. 1_2019

One, the Good, which is infinite creative power, infinitely transcendent. Man can rejoin it after a strenuous rational way, through a mystical, purely irrational experience, during the earthly limited life (Parente, 2002; Prini, 1993).

Let us consider now some of the main positions taken towards infinity over time.

\section{INFINITY IN THE GREEK WORLD}

There is a basic ambiguity in the notion of infinity in the Greek world; the definition of the term has been given either in a negative and in a positive way, but generally viewed with suspicion and restlessness.

The word "infinity" appears in Anassimandro of Mileto (about 610 BC circa $546 \mathrm{BC}$ ), which considered as the origin of the world an infinite, unlimited, indeterminate principle: the önctpov (apeiron). This is an immortal, indestructible principle, which "is not water, or anything else of what are called elements, but another generating principle, infinite, from which all contained heavens and universes are born" (Laerzio, 2005; Kahn, 1994). The Greek word önєıрov literally means "lack of limit".

Zeno of Elea (489 BC - 431 BC) is famous for his paradoxes about infinity, in particular the paradox of Achilles and the turtle (Figure 2). His paradox has been an object of attention by mathematicians and philosophers up to the present day; it is precisely the fundamental mathematical concept of limit that allows one to give a resolution to it. Zeno proposed many paradoxes for supporting the ideas of his master Parmenides of Elea (Fano, 2012).

Later, Plato (428/427 BC - 348/347 $\mathrm{BC})$ considered infinity as chaotic

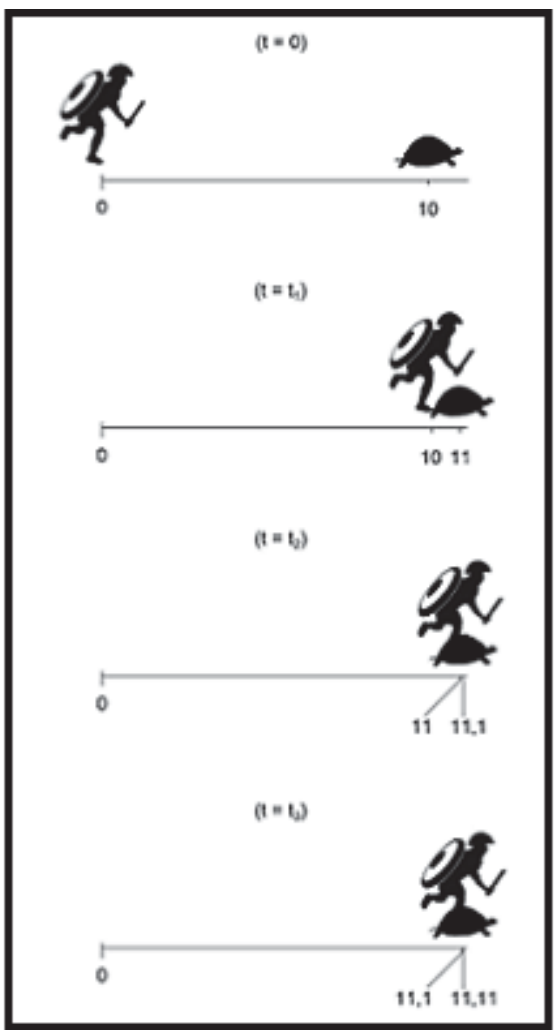

Figure 2. Representation of the paradox of Achilles and the turtle (Online ${ }^{2}$. matter, whereas the world looks like a colossal building, characterised by a well defined geometric structure. He rejected the atomistic theory of the infinity of universe and of the plurality of worlds; the geocentric theory that he proposed (the orbits of planets located between the Earth, which is at the center of universe, and the fixed stars) fits 
perfectly with the conception of unity and finiteness of the universe. In the dialogue Filebo, Plato wrote that "infinity is what is without number or measure, what is susceptible of the plus and the minus and therefore excludes order and determination" (Plato, 1982; Adorno, 2005).

The philosopher who in the Greek civilisation more deeply analysed the concept of infinity was Aristotle (384/383 BC - 322 BC). He proposed on the one hand to deny the possibility of infinity as a principle and, on the other, to justify the manifestations that, in particular in some disciplines (as for mathematics), we have of infinity (Di Sia a , 2013). In the work De Cielo, Aristotle denied the possibility of infinity as a principle through an argument "by absurd"; he supposed that there was a body of infinite dimensions and derived, from this hypothesis, consequences that can not occur. Refusing the possibility of infinity as a principle, he assumed consequently the finiteness of the world. In the work Physics, Aristotle justified the manifestations of infinity in some areas. He distinguished between the infinity by "composition or growth" (for example, in the series of natural numbers) and infinity by "division" (for example, the possibility of dividing an interval into smaller parts) (Giannantoni, 1973).

Aristotle also stated that "mathematicians, in the present state, do not feel the need for infinity (and in fact they do not use it), but only of a quantity as big as they can imagine, but always finite; then, with the same procedure they used to divide the maximum quantity, one can divide into each other one. So, the presence of infinity for the purposes of their demonstrations, it will not matter to them for in real quantities" (Berti, 1997).

This observation already contains the distinction between potential infinity and current infinity, which is one of the major contributions to the analysis of the essential characteristics of the concept of infinity.

Potential infinity relates to quantities as time, space, numbers that, despite being finite in their manifestation, can be increased or divided at will. It is a process going forward as long as we wish, without ever completing; in this sense, it is an essentially negative concept, is what is not finite. According to this meaning, this infinity has not the nothing beyond, but it has beyond always something. For example, we write a series of natural numbers as: 1, 2, 3, 4, .... the dots indicate that we can move forward how much we want; in fact, after having reached any number $n$, we can go on simply saying $n+1$. How many numbers do we have after $n+1$ ? However many we want, in principle infinite numbers. With potential infinity for growth we tend towards infinitely big, and with that by division we tend towards the infinitely small (Di Sia ${ }^{\mathrm{b}}$, 2013).

Current infinity is instead something beyond which there is nothing; it is not a process, but a property that may or may not be owned. From the viewpoint of modern mathematics, the points of a segment are infinite and constitute a current and non-potential infinity, because they are already given, in a single whole, are not built for growth as happens in the series of natural numbers, nor are obtained by successive divisions (Figure 3 ). 


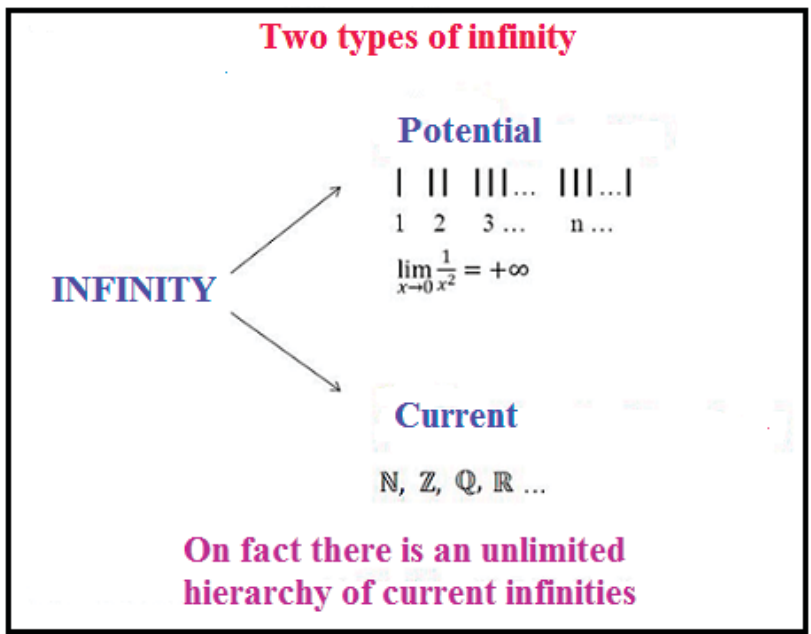

Figure 3. Potential and current infinity (Own work).

When we talk about the horror infiniti of Aristotelian philosophy, the reference is precisely to the concept of current infinity, that Aristotle believed inconsistent. In commenting on the paradox of Achilles and the turtle proposed by Zeno, Aristotle objected that there is a minimum time necessary for the fulfillment of any action and therefore it is not possible to make small at will the time taken by Achilles to travel smaller and smaller distances.

A typical expression of the horror infiniti is the suspect with which the Greek mathematician Euclid ( $4^{\text {th }}$ century BC $-3^{\text {rd }}$ century BC) looks at the $5^{\text {th }}$ postulate of his work Elements. The $5^{\text {th }}$ postulate affirms the uniqueness of a line passing through a point and parallel at another given line (Figure 4).

For Euclid two lines are parallel if, however prolonged, they do not meet. It is clear that the understanding of this postulate requires a reasoning at infinity. For this reason Euclid and mathematicians who studied his work, for two thousand years tried to prove the postulate or to replace it with more evident propositions, just to avoid the recourse to infinity. With

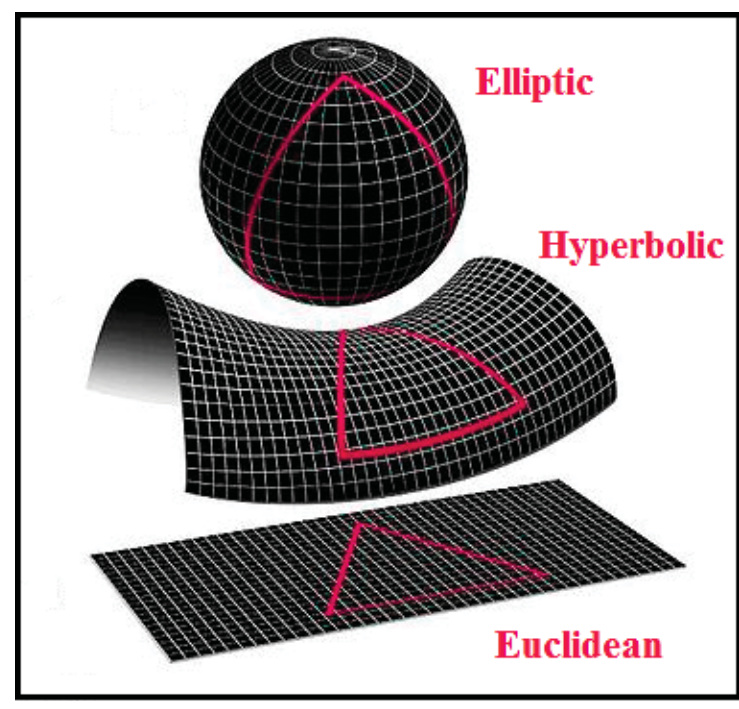

Figure 4. Euclidean and non-Euclidean geometry (Own work). 
the birth of non-Euclidean geometries, these attempts resulted not only useless and destined to failure, but also meaningless (Di Sia ${ }^{a}$, 2013; Migliorato \& Gentile, 2005).

The mathematician Archimedes (about 287 BC - 212 BC) discovered formidable results using intuitive methods based on the possibility of subdividing geometric figures into infinite parts. He felt then the need to justify these results using the method of exhaustion, just because this method made it possible to avoid the use of infinity (Di Sia, 2016; Di Sia, 2017).

In the last period of Greek philosophy, different conceptions from the Aristotelian one have been developed, in particular because the field of investigation in which they are placed was the theological one. These conceptions have as object of interest the infinite understood in its absolute sense of the first cause of the world. The intent of this research is to awaken religious and mystical experiences, but necessarily prepared by philosophical practice. These conceptions have in common, as source of inspiration, the Platonic philosophy and are called, in fact, Neoplatonic conceptions (Di Sia, 2018).

The founder of Neoplatonism is considered as being Plotinus (203/205 270). He proposed a universe characterised by a strongly hierarchical structure, at the top of which there is the One, principle and source of every being and every experience, infinite and transcendent. The One cannot be defined, because every definition or characterisation would limit its infinite transcendence. The reason may have partial access to the One only by negating a little at a time every delimitation; in reaching the One it is necessary to go beyond reason and live a mystical, ecstatic experience of enlightenment that reason prepares, but can not sustain. The One is therefore a current infinity, not reachable by the rational activity, even if it can give rise to an infinite process (in a potential sense) of approaching the One; the leap from this potential infinity to current infinity can happen only through a mystical experience of enlightenment (Pelloux, 1994).

St. Augustine (354 - 430), bishop of Hippo, in his most famous work De Civitate Dei, speaks about the current infinity and takes a different position from the Aristotelian one: "The numbers are unequal between them and different, taken individually they are finite and all together are infinite. God then, because of infinity, knows all the numbers ....." (Ratzinger, 1978).

\section{INFINITY IN THE MIDDLE AGES}

In the Middle Ages the Christian theological conceptions assigned to God the characteristics of a perfect and infinite being.

Sant'Anselmo (1033/1034 - 1109) tried to prove the existence of a very perfect, complete and infinite being.

The Franciscan theologian William of Occam (1285 - 1347) referred to a property of the infinity that at the end of the $19^{\text {th }}$ century will be used in mathematics to characterise infinite sets. Referring to a paradox of the infi- 
nity, Occam argued that "it is not impossible that the part of a quantity is not less than everything: in fact this happens whenever a part of the whole is infinite [...] so in the whole universe there are no greater parts than in a bean, because in a bean there are infinite parts. So the principle that the whole is greater than the part applies only to all compounds of finite integrant parts" (Ockham, 1967-1988).

St. Thomas (1225 - 1274) stated that the principle of things is infinite, but distinguishing between the infinity of matter and the infinity of form. The first one is imperfect, because matter without form is imperfect; the second one is instead perfection, because the infinity of form, to be, does not have need anything but itself (Fabro, 1997; Schimdt, 1966).

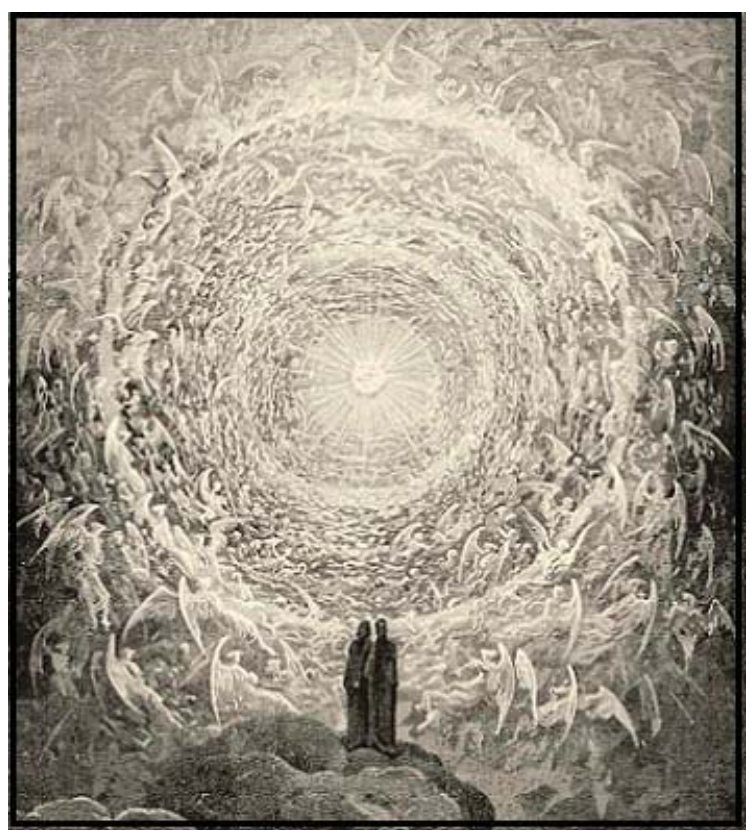

Figure 5. Dante and Beatrice contemplate the Empire, place of God's physical presence (Online $\left.{ }^{3}\right)$.

The thoughts of St. Thomas influenced deeply the Italian poet, writer and politician Dante Alighieri (1265 - 1321) and his major work, the Divine Comedy (Figure 5) (Alighieri, 2013); in it the word infinity appears in Purgatory and in Paradise, as an attribute of God and to clearly mark the distance between God and the human being. Dante refers to God as infinite and unspeakable good who is in the heavens and gives Himself to souls burning with true love. We find here the abyss that divides reason and man from God. Dante does not despise the reason; his theology, like that of St. Thomas, is the work of faith and reason and is necessary for indicating the way to reach God, but from some point onwards it is no longer enough (Marchi, 2006). 


\section{INFINITY IN THE RENAISSANCE}

At the dawn of the modern era, Niccolò Cusano (1401 - 1464) related to Neoplatonic doctrines and used a mathematical-geometric comparison to provide an image corresponding to his idea of the relation between man and God: also using correctly the cognitive tools at his disposal (sensibility, reason and intellect), man will not be able to reach the direct knowledge of God (Di Sia ${ }^{a}$, 2013; Di Siab, 2014).

For representing the fact that the intellect can approach the truth as much as it wants, but it can never understand it at all without an enlightening and ecstatic experience transcending reason, Cusano compared the knowledge of the truth reachable with the intellect to the polygons inscribed in a circle and the truth to the circle itself (Figure 6); the more angles the inscribed polygon has, the better it approximates the circle, but it is equally clear that such a polygon can never be equal to the circle (Bellatalla \& Genovesi, 2018; Di Siab, 2014).

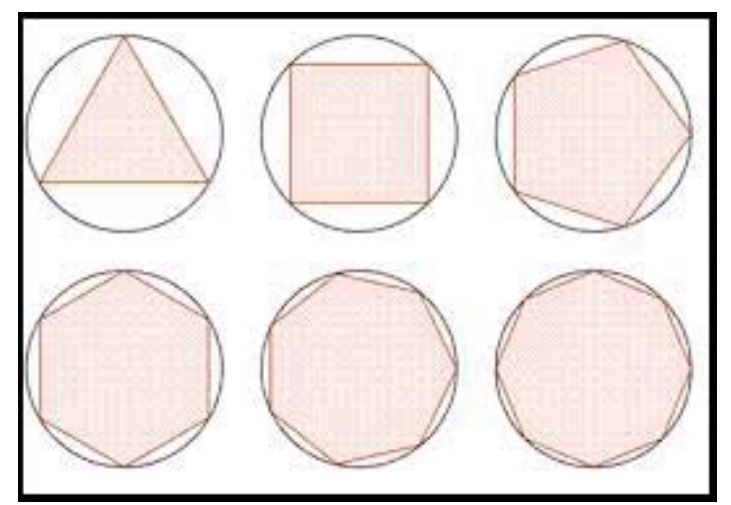

Figure 6. Increasing the number of angles of the inscribed polygon, the better it approximates to the circle (Own figure).

To the absolute, the truth, the circle, we can only arrive by following a path that transcends reason. Cusano searched continuously for symbolism and analogies suitable for describing the absolute and he often found them in mathematics, especially in geometry, rich in images that can be a good starting point for the description of the absolute.

Giordano Bruno (1548 - 1600) was influenced by the work of Copernicus; he believed that astronomy should abandon the concept of a closed, finite and limited world, replacing it with an open universe, formed by an infinity of worlds and, therefore, itself infinite. According to him, the understanding of infinity is fully realised only with mystical asceticism, which allows an identification with divinity. In this meaning, he is very close to the Neoplatonic tradition and oriental philosophies (Di Sia ${ }^{\mathrm{b}}$, 2014; del Giudice, 2009).

Over the centuries, from Aristotle to Gauss, various ideas introduced into mathematics the need to study and define infinity and also its mathematical inverse (the infinitesimal) in their forms. In the $17^{\text {th }}$ century (and also earlier), the 
need to ensure an adequate theoretical basis for the study of physical quantities such as velocity, acceleration and so on, led Isaac Newton (1642 - 1727), Gottfried Wilhelm von Leibniz (1646 - 1716) and others to create (with some imprecisions, some vagueness and much controversy) differential calculus, the relative study of derivatives and just the use of infinitesimals (Di Sia $\left.{ }^{b}, 2014\right)$.

The goal was to describe in rigorous mathematical terms the behaviour of a function, when it approaches indefinitely to a point, or tends indefinitely to infinity (Figure 7).

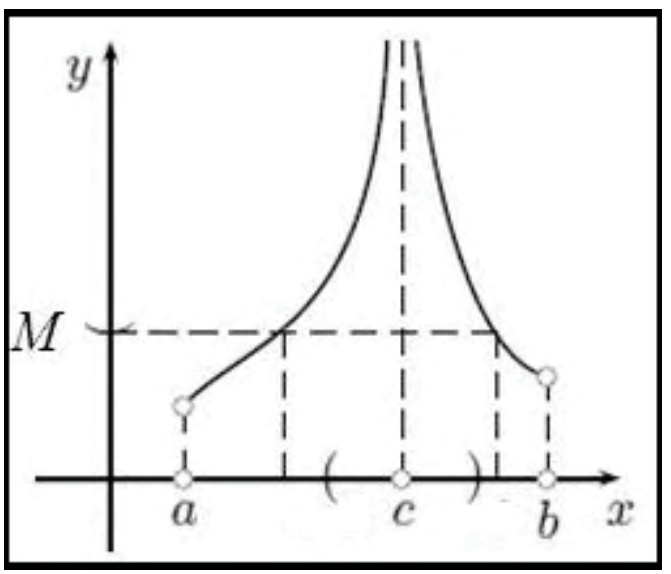

Figure 7. A function approaching $a$ and $b$ and the infinity in $c$ (Own work).

Galileo Galilei (1564 - 1642) considered the natural numbers 0, 1, 2, 3 ... and observed that the (infinite) set of their squares $0,1,4,9, \ldots$ is certainly smaller but, nevertheless, contains as many elements as the starting numbers, because to each number corresponds in a bijective way its square. Galileo's reflections germinally contain stimulating suggestions on how we could pretend to measure infinity. In fact, we cannot count the natural numbers nor their squares (both infinite); nevertheless, we can compare them and strictly establish that the first ones are as many as the second ones, because there is a bijective correspondence between their sets. Therefore, to infinity, we can, if not count, just compare and decide whether two sets are equally numerous or not. The idea is brilliant and subtle (Heilbron, 2013).

\section{INFINITY IN ROMANTIC TIME AND BEYOND}

The work of mathematicians Augustin-Louis Cauchy (1789 - 1857) and Karl Theodor Wilhelm Weierstrass (1815 - 1897) produced a good response to the problems of Newton and a rigorous theoretical introduction to this delicate subject, through the definition of the concept of limit, that reveals itself to be an elegant and deep approach to potential infinity in mathematics (Di Sia ${ }^{\mathrm{b}}, 2014$; Di Sia ${ }^{a}$, 2017). 
In his posthumous work Paradoxes of infinity, Bernard Placidus Johann Nepomuk Bolzano (1781 - 1848) observed how the closed segment [0,5] of the real line has as many points as the evidently larger interval [0,12] (Bolzano, 2003).

According to a romantic sensibility, the artwork is not a result of intelligence, nor of study or learning, but of genius, intuition, the creative force that the artist possesses as a gift of Nature. The artist is the one who can mediate between infinity and the world; infinity, beyond of everyday experience, cannot be perceived, nor explained by the rules of logic, of rational thought. It can only be felt by those who have a refined sensitivity, being able to transcend the limits imposed by reason and daily experience. Already in Neoclassicism we find some typically romantic attitudes:

- the nostalgia for a vanished golden age;

- the sense of death;

- the conscience to live life in full ardour ;

- the yearning for freedom.

In the field of art, painting was affected by the most typical romantic feelings, but also architecture and sculpture, linked to the laws of statics and to three-dimensional reality. In painting there is the illusion of inventing spaces, shapes, techniques and colours, for not representing the outside world, but the way in which the artist sees, feels and lives this world. Especially in Germany, England and France, i.e. in the areas where Romanticism was born and codified, artists expressed clearly the yearning for the infinite and sublime, searching for expressive forms allowing them to overcome limits and constraints of reality and everyday experience.

One of these artists was Caspar David Friedrich (1774 - 1840). In his paintings it is possible to live the tension of limited and finite man towards infinity, towards a world transcending the daily experience, to which he can somehow approach thanks to the artistic experience. In his landscapes we see the search for the sublime, the sense of dismay and attraction that man feels in front of the greatness and power of Nature. Through the search for the sublime, man can feel infinity and realise that the limited feeling experience can be transcended through art and poetry.

The painting The sea of ice depicts a polar landscape, the sea on which mountains and slabs of lighted ice rise, up to the horizon (Figure 8).

This landscape reminds us the greatness and power of Nature, dominating the small and fragile finite man, just as small and fragile appears the overturned boat, almost covered by ice, drowned in that terrible and attractive landscape, perhaps indifferent to human travails. The painting has a transparent symbolic meaning: the yearning for knowledge, the hope of being able to dominate Nature are destined to be defeated.

Even in Hiker on the sea offog (Figure 9), Friedrich expresses the contrast between the greatness of Nature and the man's finiteness. A man looks at the distant mountains, that, because of the fog, seem to get lost into infinity. Infinity opens up like a terrible abyss and at the same time attractive, a different world by that of human experience, small and limited in time and space (Vaughan, 2004; Wolf, 2003). 


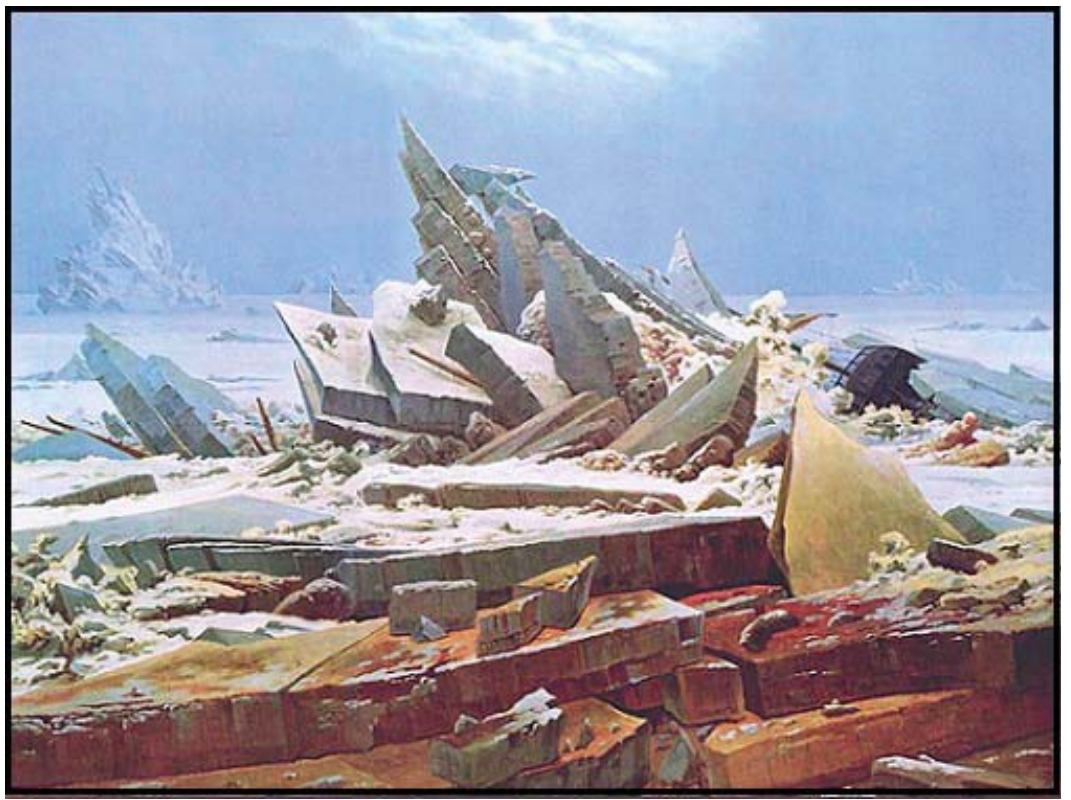

Figure 8. The sea of ice (Online $\left.{ }^{4}\right)$.

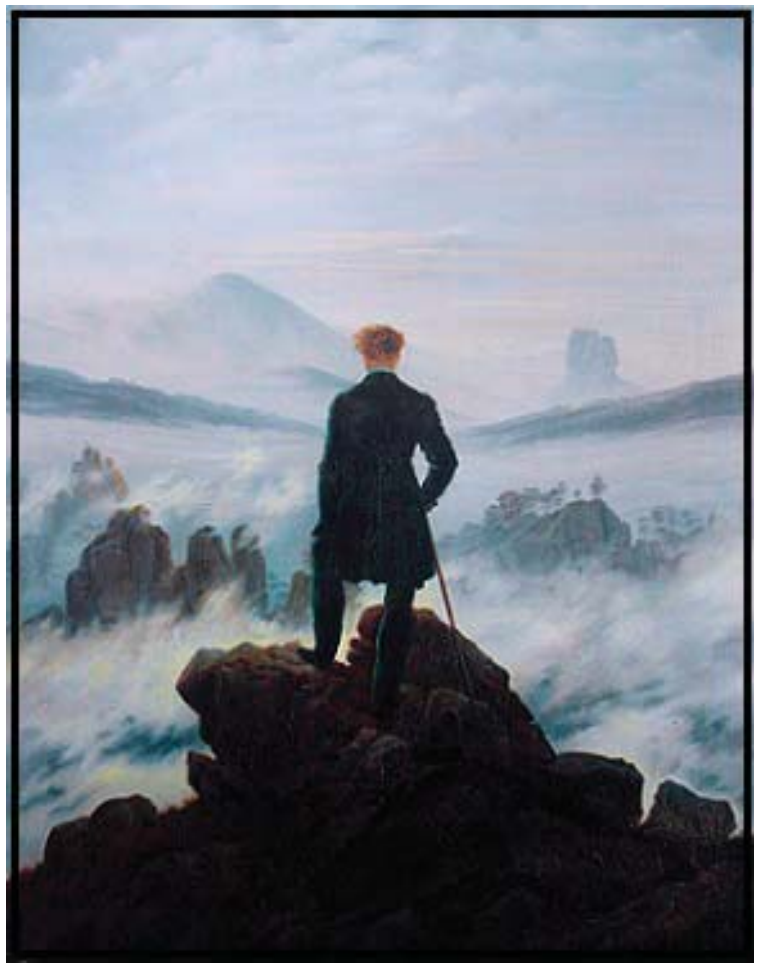

Figure 9. Hiker on the sea of fog $\left(\right.$ Online $\left.^{5}\right)$. 
In England, among the interpreters of this component of the romantic spirit, we have the poet and painter William Blake (1757 - 1827) and the painter Joseph Mallord William Turner (1775 - 1851). Blake tried to translate his imaginary, dreamlike world into his artistic production, in works such as The house of death (Figure 10) (inspired by the Lost Paradise of John Milton) and Paolo and Francesca (inspired by the Canto $V$ of Dante's hell).

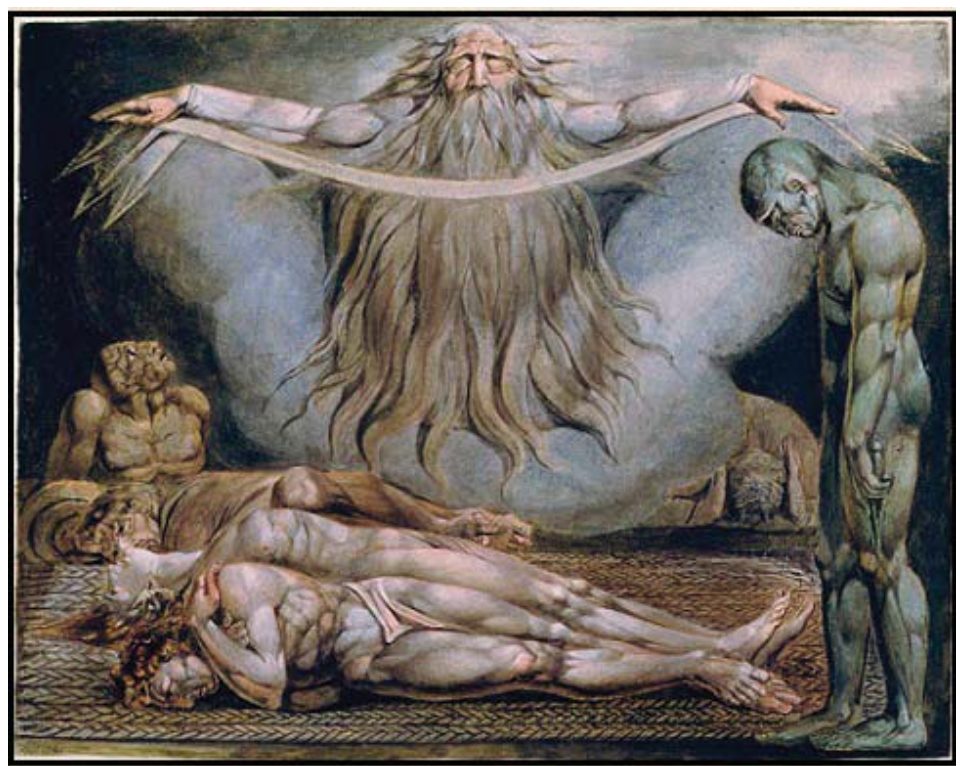

Figure 10. The house of death $\left(\right.$ Online $\left.^{6}\right)$.

Both paintings reveal a fantastic and hallucinated fantasy, looking for something not belonging to the sphere of everyday life or rationality (Ault, 1987; Bentley Jr., 2001).

Turner, one of the greatest English painters, tried to translate the loss of man in front of the greatness of Nature, through a particular attention to light and colour, to the detriment of form and perspective view, in works such as Rain, steam and speed (Figure 11) (Hamilton, 2008).

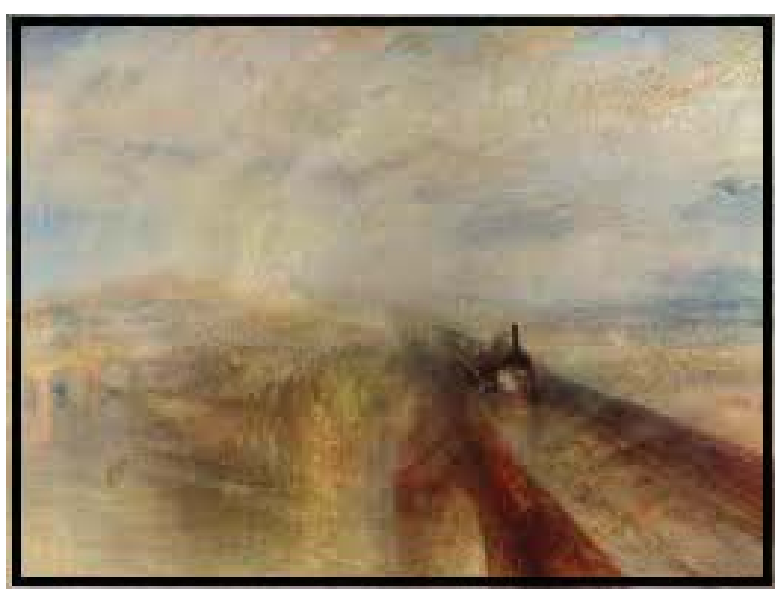

Figure 11. Rain, steam and speed (Online ${ }^{7}$. 


\section{INFINITY IN THE LAST CENTURY}

In different forms, the tension centered on yearning for infinity and overcoming the daily dimension characterises even non-Romantic artists and other movements. In particular we underline the Cubism, the Expressionism and Abstractism.

Cubism was born with Pablo Picasso (1881 - 1973) and Georges Braque (1882 1963), with the program, as Picasso said, "to express all that was in us". Their thesis was that reality, the outside world should not only be represented, but understood; they imputed to Impressionist painters preceeding them to have used only the retina instead of the brain (Galluzzi, 2002). The cubists search to filter reality through the artist's self, characterizing the artwork with a strong component of subjectivity. It is an overcoming of the mono-prospective vision, for representing reality in its own globality, from within (Figure 12).

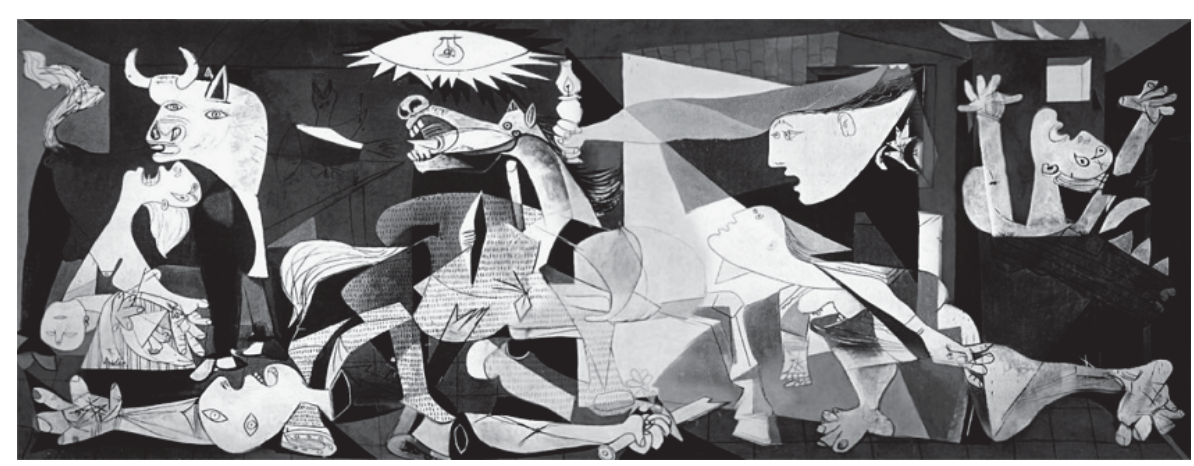

Figure 12. Picasso: Guernica $\left(\mathrm{Online}^{8}\right)$.

Cubists want to give of the represented object a not only spatial, but also temporal dimension. The $4^{\text {th }}$ dimension is present to the spirit, from a plastic point of view, as generated by the three known measures; it represents the immensity of space that, at a given time, rushes towards infinity in all directions.

The anxiety of which the existentialist philosopher Søren Aabye Kierkegaard (1813 - 1855) speaks has been beautifully depicted in The Scream of Edvard Munch (1863 - 1944) (Figure 13): arms, hands, head, the whole figure and the landscape itself seem to sway, perturbed by this silent, terrible scream emitted at very low frequency, but that, as

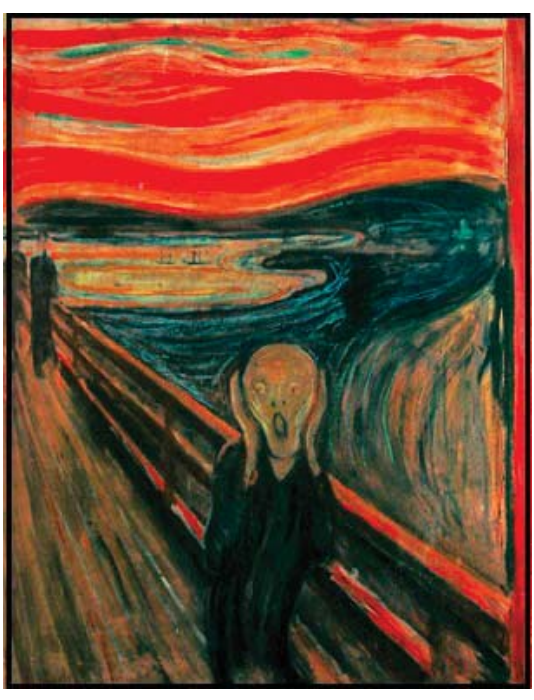

Figure 13. Munch: The Scream $\left(\right.$ Online $\left.^{9}\right)$. 
Munch said, comes from all of Nature. It is a scream of distress, felt only when one has the misfortune of looking inside the abyss of himself (Nicosia, 2003).

The objective of overcoming the representation of outer reality continued with Expressionists, who were influenced by Munch and found in Blake an illustrious predecessor.

The Austrian expressionist Oskar Kokoschka (1886 - 1980) considered some themes of the late Romantic period, such as the necessity to look at reality with the eyes of a child, just to give wide freedom to one's own interpretation, not conditioning it with overstructures. In his work The Bride of the Wind (Figure 14), a man and a woman are dragged by a storm to infinity.

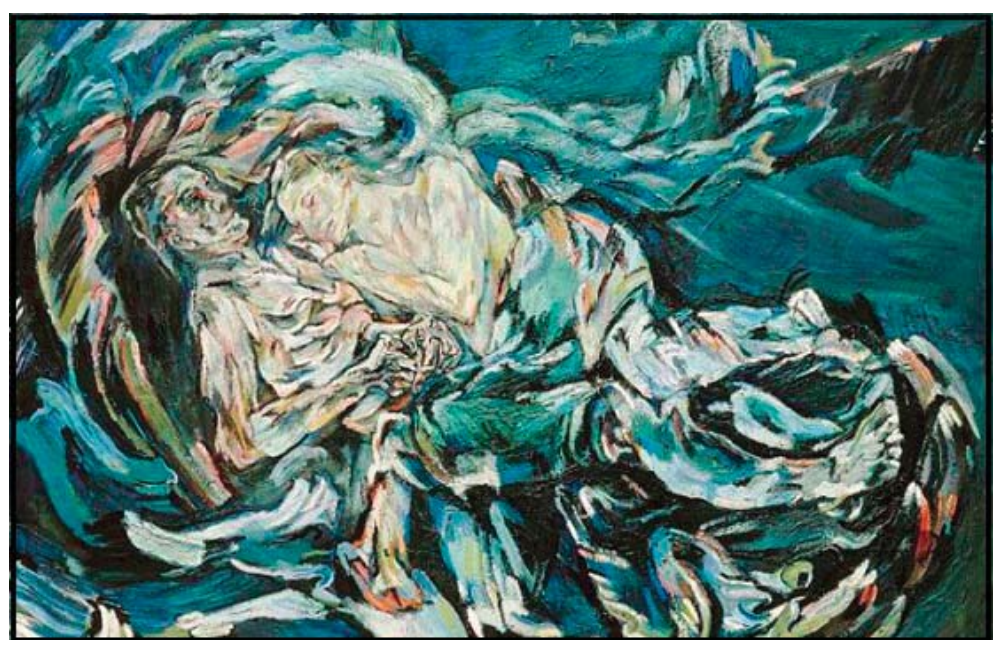

Figure 14. Kokoschka: The Bride of the Wind $\left(\right.$ Online $\left.{ }^{10}\right)$.

Abstractism has been considered the highlight of a process aimed at denying art the task of representing the outer reality; the art must represent the inner feeling, the deepest sensations. The artist's vision is represented by lines and geometric shapes: what better language than that of geometry and of mathematics to talk about what is difficult to represent? Abstractism is an artistic form approaching that of music: as the musician expands or contracts time intervals following a rhythm reflecting his mood, so the painter associates colours, lights, spaces, lines in a rhythm dictated from his inner feeling. With Abstractism the parallel between painting and music becomes stronger; art critics begin to speak about tones, timbres, while music critics qualify sounds as bright, dark. Abstractists attribute to colours the ability to arouse feelings (Figure 15).

Vasilij Vasil'evič Kandinsky (1866 - 1944) wrote in this regard: "The tendency of blue to the deepening is such that, in the darker gradations, it becomes more intense and exerts a more typical inner action. As it becomes deeper, the more it invites man to infinity, awakens in him the desire of the pure, the over-sen- 


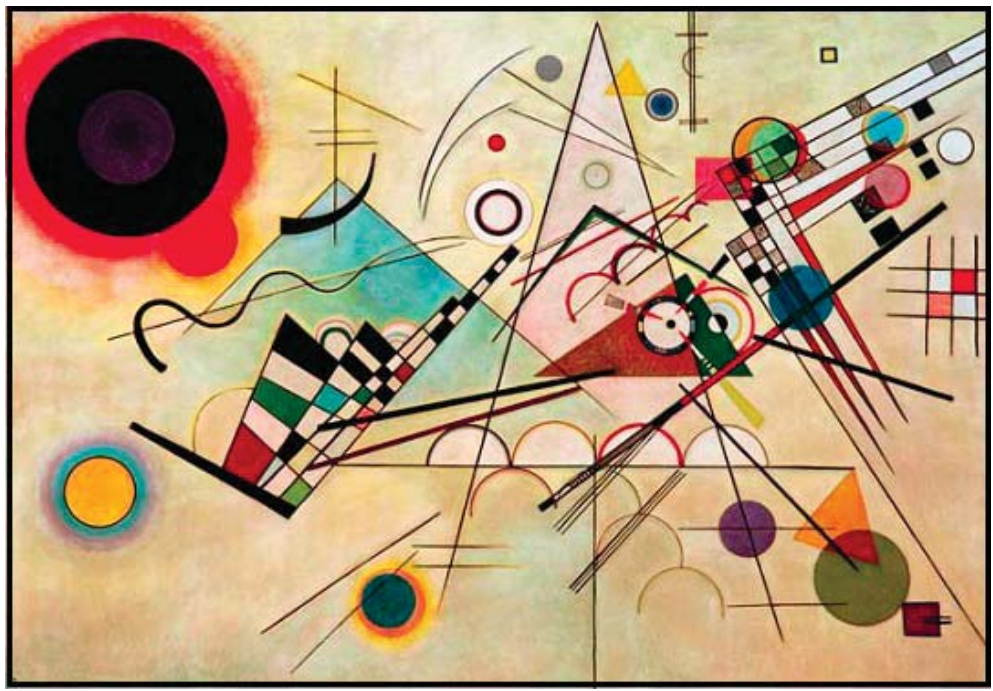

Figure 15. Kandinsky: Composition VIII (Online $\left.{ }^{11}\right)$.

sible. It is the colour of the sky, as we represent it when we hear the sound of the word sky" (Kojève, 2005). Shapes and colours are evocative of images of the inner world, of the infinity that has lived always as something other than the experience of man.

The German mathematician Georg Ferdinand Ludwig Philipp Cantor (1845 - 1918), father of modern set theory, gave the fundamental and decisive turning point to the whole question. He observed that there are as many points in the whole real line as in the open segment $\mathbf{A B}$, which is enormously smaller (Figure 16).

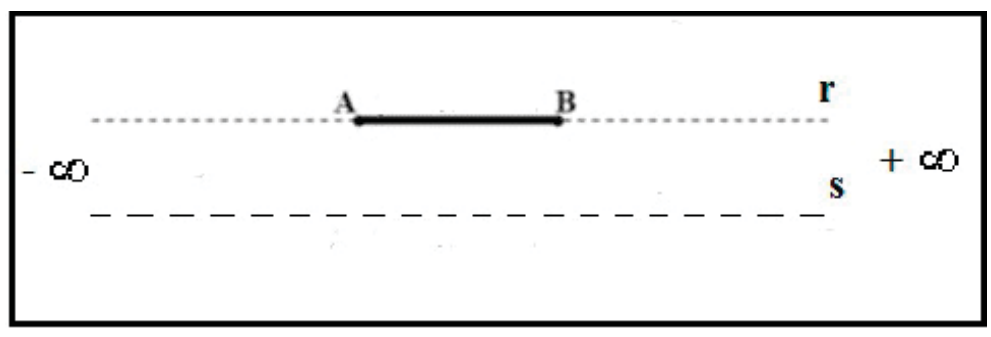

Figure 16. A line and a "part" of it (Own figure).

Other cases have been explored by Cantor. We list some particularly significant:

a) We could evaluate roughly the set $\mathrm{N}$ of the natural numbers: $0,1,2, \ldots$ how the half of the set $\mathrm{Z}$ of all the integers: ...- 2, -1, $0,1,2, \ldots$; but they are both infinite, and indeed it is possible to determine a bijective correspondence connecting them. Just let's observe that natural numbers are divided in half between even $(0,2,4, \ldots)$ and odd $(1,3,5, \ldots)$; we can transform 
the non-negative integers in the first series and the negative ones in the second series. In rigorous terms, to fix for every natural $x$ :

$$
\begin{gathered}
f(x)=2 x, \text { if } x \neq 0 \\
f(x)=-2 x-1, \text { otherwise. }
\end{gathered}
$$

b) This was the ingenious argument with which Cantor demonstrated in 1895 that naturals are as many as rationals (Cantor had already reached this conclusion in 1874, but using a different and more complicated demonstration) (Cantor, 1915, 1955).

c) Another surprising result of Cantor connects the square (the cube) with its side (faces): the former one and the latter one have the same number of points. The theorem was proved in 1877 and aroused disbelief and bewilderment among the mathematicians of the time; Cantor himself was somewhat surprised and commented it in a letter to Julius Wilhelm Richard Dedekind (1831 - 1916) with the words: "I see it, but I do not believe it".

The reason for such amazement is easy to understand: the result seems to confuse curves, surfaces and volumes and therefore geometric entities of dimensions 1, 2 and 3, putting down any distinction in this regard and, ultimately, undermining the same foundations of geometry. But it was (and is) only a superficial impression, understandable in a time that had not still fully developed the concept of topological space. As Dedekind clearly observed, Cantor's bijections are just bijections and do not have that requirement of continuity which contradict so many certainties. Segment, square, cube have the same number of points, but for this they are not homeomorph among them (a homeomorphism is a particular function between topological spaces that provides the intuitive idea of "deformation without tearing").

d) The same reasoning can be used to prove that the straight line $\mathrm{R}$ has as many points as the two-dimensional plane $\mathrm{R}^{2}$ or the three-dimensional space $\mathrm{R}^{3}$ (Di Sia ${ }^{\mathrm{b}}$, 2014; Dauben, 1979).

These examples confirm the superficial impression mentioned above. All infinite sets have the same number of elements, precisely because they are infinite. Add or removing an element, or two elements, or even more elements, does not alter the total number. Therefore, it is not worth using sophisms for distinguishing between counting and comparing, and attempting an unlikely measurement of an infinity that does not want be measured.

The previous observations can be used:

a) to give a precise and convincing mathematical definition of what is an infinite set;

b) accepting the proposal forwarded by Dedekind in 1888 (in the work The Finite and the Infinite) (Moore, 2012) to call infinite a set A when it can be put in a bijective correspondence with an own proper subset. This condition cannot be satisfied in the finite contexts. 
Still staying on the subject of how to define infinity, Cantor proposed (with respect to Dedekind) a formally different approach. Contrary to what all the previous examples presaged, in 1874 Cantor showed that not all infinities are equal; there are more possible ways of being infinite. The most famous evidence, commonly cited today in the sets theory manuals and that use the commonly called diagonalisation, is dated to 1891 . There are at least two distinct ways of being infinite, that of natural (integer, rational) numbers and that of real numbers (and of every interval or half-line of $\mathrm{R}$ ). This was an amazing result, considering the historical context in which it matured.

Cantor generalized the result and proved that there are even an infinite number of different ways of being infinite, as follows by one of his theorems in 1883, then perfected in an easier demonstration of 1892. Thus, for example, the number of naturals is different from that of sets of naturals and from that of sets of naturals sets and so on, in a process producing always new infinities. Now, the disparity of elements between a set and the set of its parts is a well known result in the finite context; it is a simple and classic application of the principle of induction. But the novelty of Cantor's work is that the fact also moves to infinite cases.

The question has religious implications too; infinity seems a subject more adequate for theologians and philosophers than for mathematicians. Cantor was a good believer and was also involved in theology; he tried to deepen the question between 1885 and 1888, and arrived at distinguishing two possible current infinities:

1) the first one, called by him Absolute Infinity, applies only to God, is a theme of religion and can not be humanly scientifically perceived and approached;

2) the second one, which he baptized transfinity, for underlying its difference from the previous one, is the infinity of mathematics, on which everyone can work (Di Siab , 2014; Yarnelle, 1966).

Resolved with the Nulla Osta of the religious authorities of Rome the theological question, Cantor had to overcome the diffidence of the scientific community for his new mathematical theories. His work clashed clearly with the Aristotelian dictate and against the opinion of illustrious contemporary and previous mathematicians. Even Leopold Kronecker (1823 - 1891), Cantor's teacher during his university studies in Berlin, refuted his discoveries, saying: "Cantor's work on transfinite numbers and set theory is not mathematics, but mysticism", and added that "positive integers are the only ones created by God; everything else is man's work" (Bell, 1986). Conversely, other great mathematicians appreciated the Cantor's work and welcomed it with enthusiasm. Cantor had opened to man the infinity of angels, a long hidden paradise, considered inaccessible for millennia.

David Hilbert (1862 - 1943), a German mathematician, welcomed Canto$r^{\prime}$ s work and the consequent introduction and definition of current infinity in mathematics; his research in those years gave original contributions to the topic. In 1899 he proposed in the work Grundlagen der Geometrie (Hilbert, 1970) a new arrangement of elementary geometry, which exceeded the specific area 
to which it applied, and investing the global way of conceiving mathematics. Hilbert's approach gave particular emphasis to the role of axioms, as fundamental bases for the development of the whole theme. This reference to the axioms was not original, but directly related to the tradition of Euclid. However, not negligible differences distinguished the ancient Greek mentality from Hilbert setting and, among these, the most substantial was the different role that was attributed to these propositions.

In the following years, Hilbert made further contributions to the development of mathematics with the axiomatic method. In 1900, in the work Über den Zahlbegriff (Online $\left.{ }^{12}\right)$, he developed a system of postulates for real numbers and posed the question of consistency of arithmetic, i.e. the possibility of excluding every intrinsic contradiction. Hilbert came back to the question of mathematics of infinity in 1917 with the work Axiomatisches Denken (Online ${ }^{13}$ ) and presented, between 1920s and 1930s, the general characters of his famous program, to which contributed famous mathematicians like Wilhelm Friedrich Ackermann (1896 - 1962), Paul Isaac Bernays (1888 - 1977) and John von Neumann (1903-1957). This program deepened and generalised the conception of geometry according to the essential lines summarised below:

a) All sufficiently developed mathematical disciplines must have their own system of axioms and rules of reasoning, which allow the formation of finite sequences of propositions, i.e. the demonstrations, of which theorems represent the last steps.

b) The fundamental requirement that each of these formal systems must satisfy is the intrinsic coherence. Indeed the absence of contradictions constitutes the only discriminating criterion of accreditation.

In this perspective, Cantor's mathematics of infinity finds full citizenship rights. Mathematics can well include the concept of Infinity (with capital "I"), provided that its formal system satisfies the basic requirement of coherence. In this way the finite methods of science and the apparent transcendence of the theme come to be reconciled. The work in which Hilbert better developed this concept in 1925 is entitled About t infinity (Cellucci, 2007).

The mathematician Kurt Friedrich Gödel (1906-1978) dedicated to Hilbert's problem a finitary demonstration of the consistency of arithmetic. His original intention was to contribute to the realisation of the Hilbertian program. But, examining the question of coherence and in particular developing a delicate reflection on the necessary means to demonstrate it, he arrived at results of a completely opposite indication with respect to expectations and as such sunk Hilbert's hopes.

The first fundamental result that Gödel published in 1931 (in an article published in Monatshefte für Mathematik und Physik, entitled On the formally undecidable propositions of the Principia Mathematica and of related systems) states:

$1^{\text {st }}$ Gödel incompleteness theorem. In any formal system S one can construct propositions that the system cannot decide; they can not be proved nor refuted on the basis of axioms and rules of system deduction.

A second Gödel result undermined also the qualifying property of consistency, thus causing the collapse of the Hilbert's program. 
$2^{\text {nd }}$ Gödel incompleteness theorem. No formal system S including the elementary theory of numbers and without contradictions will be able to self-certify (then to demonstrate within it, starting from axioms and using the rules of deduction) its own coherence (Gödel, 1986-2006; Online ${ }^{14}$ ).

Therefore, it seems that man is not able to understand the fundamentals of mathematics, formulating them in a definitive and complete way; however, he knows how to recognise his incapacity, to the point of demonstrating it in a mathematically rigorous way. In this sense, Gödel's theorems can also be understood, like the hedge of the Italian poet Leopardi, like the mark of a limit that prevents us, but does not hide from us a reality that transcends our dimension. After all, the French mathematician, physicist, philosopher and theologian Blaise Pascal (1623 - 1662) observed with his clear style in Thought 188-267: "The last step of reason is to recognise that there are infinite things that overcome it" (Pascal, 1995). Neither Gödel nor mathematics can totally clarify what is this reality that transcends us, if a divinity, or chaos or other.

André Weil (1906 - 1998), French mathematician, one of the greatest of the $20^{\text {th }}$ century, said that Gödel's theorems demonstrate the existence of God as of the devil: God because mathematics is coherent, the devil because we can not anyway demonstrate its coherence (Weil, 2014; Weil \& Weil, 2018; Di Sia ${ }^{b}, 2017$; Di Sia, 2019).

\section{CONCLUSIONS}

The human being meets the idea of infinity very early in life, when he realises that the process of counting has no end; when this happens, the child no longer abandons this concept. Infinity attracts and rejects, becoming object of desire, study and systematic research. Since ancient times, the greatest thinkers have tried to profoundly understand this concept, creating ever more refined theories and models.

Art, poetry, music, philosophy, mathematics have tried and try to capture infinity Man does not completely dominate mathematics and understand its foundations, in such a way as to reduce it to a pure simple computer-based deduction game. This incapacity is already registered in the context of natural numbers. Mathematics of Infinity (and the Hilbert's hope of a self-certified coherence) must share the same embarrassing situation.

However, all this does not exclude the general study and deepening of mathematics and culture of infinity. Substantial fascinating and stimulating progress has been achieved in recent years. Gödel's results remain still a fundamental point of reference on the true nature of mathematics, even if embarrasses and disturbs mathematicians. 


\section{REFERENCES}

[1] Adorno, F. (2005). Introduzione a Platone [Introduction to Plato]. Roma-Bari: Laterza.

[2] Alighieri, D. (2013). The divine comedy. Oxford: Oxford University Press.

[3] Ault, D. (1987). Narrative Unbound: Re-Visioning William Blake's The Four Zoas. Barrytown, NY: Station Hill Press.

[4] Bell, E. T. (1986). Men of Mathematics. New York: Simon and Schuster.

[5] Bellatalla, L., Genovesi, G. (2018). Il De docta ignorantia di Niccolò Cusano. «Sub specie educationis». Roma: Anicia.

[6] Bentley Jr., G. E. (2001). The Stranger From Paradise: A Biography of William Blake. Yale: Yale University Press.

[7] Berti, E. (1997). Guida ad Aristotele [Guide to Aristotle] Roma-Bari: Laterza.

[8] Bolzano, B. (2003). I paradossi dell' infinito [The paradoxes of the infinity], Torino: Bollati Boringhieri.

[9] Borges, J. L. (1976). Otras inquisiciones [Other inquisitions]. Madrid: Alianza.

[10] Cantor, G. (1955, 1915). Contributions to the Founding of the Theory of Transfinite Numbers. New York: Dover.

[11] Cellucci, C. (2007). La filosofia della matematica del Novecento [The philosophy of mathematics of the twentieth century]. Roma: Biblioteca Essenziale Laterza.

[12] Dauben, J. W. (1979). Georg Cantor: his mathematics and philosophy of the infinite. Boston: Harvard University Press.

[13] del Giudice, G. (Ed.). (2009). Il dio dei Geometri - quattro dialoghi [The god of Geometry - four dialogues]. Roma: Di Renzo Editore.

[14] Di Sia, P. (2005). Un intervento sull'evoluzione dei concetti di spazio e tempo [An intervention on the evolution of the concepts of space and time], Periodico di Matematiche (Mathesis), VIII, 5(3), 55-68.

[15] Di Sia, P. (2015). Approaching youngs to unified theories: the charm of string theories. Procedia - Social and Behavioral Sciences Journal (Elsevier), 174C, 10-16.

[16] Di Sia, P. (2016). A Historical-Teaching Introduction to Algebra. International Letters of Social and Humanistic Sciences (ILSHS), 66, 154-161. DOI: 10.18052/www.scipress. com/ILSHS.66.154.

[17] Di Sia, P. (2018). Fisica moderna, coscienza, multiverso, azione divina. Problemi, dubbi, convergenze [Modern physics, consciousness, multiverse, divine action. Problems, doubts, convergences]. Roma: Stamen.

[18] Di Sia, P. (2019). On new technologies for studying and learning mathematics. E-methodology (review process).

[19] Di Sia a, P. (2013). Fondamenti di Matematica e Didattica I [Foundations of Mathematics and Didactics I]. Roma: Aracne.

[20] Di Sia a, P. (2014). Describing the concept of "infinity" among art, literature, philosophy and science: a pedagogical-didactic overview. Journal of Education, Culture and Society, 1, 9-19, DOI: 10.15503/jecs20141-9-19.

[21] Di Siaa, P. (2017). A Hystorical-Didactic Introduction To The Key Concepts Of Mathematical Analysis. TOJET (The Online Journal of Educational Technology), 60-68.

[22] Di Siab, P. (2013). Elementi di Didattica della Matematica I - Laboratorio [Elements of Didactics of Mathematics I - Laboratory]. Roma: Aracne.

[23] Di Sia ${ }^{\text {b }, ~ P . ~(2014) . ~ F o n d a m e n t i ~ d i ~ M a t e m a t i c a ~ e ~ D i d a t t i c a ~ I I ~[F o u n d a t i o n s ~ o f ~ M a t h e m a t i c s ~}$ and Didactics II]. Roma: Aracne.

[24] Di Siab, P. (2017). Learning mathematics through games in primary school: an applicative path. Edutainment 1(1), 127-133. https://jecs.pl/index.php/EDUT/ article/view/10.15503.edut.2016.1.127.133. 
Journal of Education Culture and Society No. 1_2019

[25] Fabro, C. (1997). Introduzione a San Tommaso. La metafisica tomista e il pensiero moderno [Introduction to St. Thomas. Thomist metaphysics and modern thought]. Milano: Ares.

[26] Fano, V. (2012). I paradossi di Zenone [The paradoxes of Zeno]. Roma: Carocci.

[27] Galluzzi, F. (2002). Picasso. Firenze: Giunti Editore.

[28] Giannantoni, G. (Ed.). (1973). Opere [Works]. Bari: Laterza (4 vols.).

[29] Gödel, K. (1986-2006). Collected Works. New York: Oxford University Press (5 volumes, texts in German with English translation in front).

[30] Hamilton, J. (Ed.). (2008). Turner e l'Italia [Turner and Italy]. Ferrara: Ferrara Arte.

[31] Heilbron, J. L. (2013). Galileo. Scienziato e umanista [Galileo. Scientist and humanist]. Torino: Einaudi.

[32] Hilbert, D. (1970). Fondamenti della geometria [Foundations of geometry]. Torino: Feltrinelli.

[33] Kahn, C. H. (1994). Anaximander and the Origins of Greek Cosmology (3 ${ }^{\text {rd }}$ ed.). Indianapolis: Hackett.

[34] Kojève, A. (2005). Kandinsky. Macerata: Quodlibet.

[35] Laerzio, D. (2005). Vite e dottrine dei più celebri filosofi [Lives and doctrines of the most famous philosophers]. Milano: Bompiani.

[36] Marchi, C. (2006). Dante. Milano: RCS.

[37] Migliorato, R., Gentile, G. (2005). Euclid and the scientific thought in the third century BC. Ratio Mathematica, 15, 37-64.

[38] Moore, G. H. (2012). Zermelo's Axiom of Choice: Its Origins, Development, and Influence. Berlin: Springer Science \& Business Media.

[39] Nicosia, F. (2003): Munch. Firenze: Giunti Editore.

[40] Ockham, W. (Gál G. et alii (Eds)) (1967-1988). Opera philosophica et theologica. New York: The Saint Bonaventure University Press.

[41] Parente, M. I. (2002). Introduzione a Plotino [Introduction to Plotinus]. Roma-Bari: Laterza.

[42] Pascal, B. (Vozza, C. (Ed.)) (1995). Pensieri [Thoughts]. Rimini: Guaraldi.

[43] Pelloux, L. (1994). L'assoluto nella dottrina di Plotino [The absolute in Plotino's doctrine]. Milano: Vita e Pensiero.

[44] Plato. (1982-1984) (Giannantoni G. (Ed.)). Opere complete [Complete Works]. Laterza, Roma-Bari (9 vols.).

[45] Prini, P. (1993). Plotino e la fondazione dell'umanesimo interiore [Plotinus and the foundation of inner humanism]. Milano: Vita e Pensiero.

[46] Ratzinger, J. (1978). Popolo e casa di Dio in Sant'Agostino [People and the house of God in St. Augustine]. Milano: Jaca Book.

[47] Schimdt, R. (1966). The Domain of Logic According to Saint Thomas Aquinas. L'Aia: Martinus Nijhoff.

[48] Vaughan, W. (2004). Friedrich. Oxford: Phaidon Press.

[49] Weil, A. (Argentieri, N. (Ed.)) (2014). La fredda bellezza. Dalla metafisica alla matematica (Cold beauty. From metaphysics to mathematics). Roma: Castelvecchi.

[50] Weil, A., \& Weil, S. (Chenavier, R., Devaux, A. A., Sala, M. C. (Eds)) (2018). L'arte della matematica [The art of mathematics]. Milano: Adelphi.

[51] Wolf, N. (2003). Caspar David Friedrich. Colonia: Taschen.

[52] Yarnelle, J. E. (1966). An Introduction to Transfinite Mathematics. Lexington, Massachusetts: DC Heath.

[53] Available online ${ }^{12}$ (January 30, 2019): https://www.digizeitschriften.de/dms/ toc/?PID=PPN37721857X_0008.

[54] Available online ${ }^{13}$ (January 30, 2019): https:/ / eudml.org/doc/158776.

[55] Available online ${ }^{14}$ (January 31, 2019): http:// bauhaus77.blogspot.com/2012/02/ kurt-godel-my-philosophical-viewpoint.html. 


\section{FIGURES}

Figure 1. Available online ${ }^{1}$ (January 26, 2019): https://it.wikipedia.org/wiki/Ecumene\#/media/File:Herodotus_world_map-en.svg.

Figure 2. Available online ${ }^{2}$ (January 26, 2019): https://it.wikipedia.org/wiki/Paradosso_di_Achille_e_la_tartaruga\#/media/File:Achilles_and_turtle.png.

Figure 5. Available online ${ }^{3}$ (January 26, 2019): https://it.wikipedia.org/wiki/Paradiso_(Divina_Commedia)\#/media/File:Paradiso_Canto_31.jpg.

Figure 8. Available online (January 28, 2019): https://it.wikipedia.org/wiki/Caspar_ David_Friedrich\#/media/File:Caspar_David_Friedrich_-_Das_Eismeer_-_ Hamburger_Kunsthalle_-_02.jpg.

Figure 9. Available online ${ }^{5}$ (January 28, 2019): https://it.wikipedia.org/wiki/ Caspar_David_Friedrich\#/media/File:Caspar_David_Friedrich_-_Wanderer_above_the_sea_of_fog.jpg

Figure 10. Available online ${ }^{6}$ (January 28, 2019): https://www.wikiart.org/en/ william-blake/the-house-of-death.

Figure 11. Available online ${ }^{7}$ (January 28, 2019): https://en.wikipedia.org/wiki/ Rain,_Steam_and_Speed_\%E2\%80\%93_The_Great_Western_Railway.

Figure 12. Available online ${ }^{8}$ (January 30, 2019): https://www.arteworld.it/wp-content/uploads/2016/05/Guernica-Pablo-Picasso-analisi.jpg.

Figure 13. Available online ${ }^{9}$ (January 30, 2019): https://it.wikipedia.org/wiki/ Edvard_Munch\#/media/File:The_Scream.jpg.

Figure 14. Available online ${ }^{10}$ (January 30, 2019): https://www.sensazionidarte.it/ oskar-kokoschka-la-sposa-del-vento-1914/.

Figure 15. Available online ${ }^{11}$ (January 30, 2019): https://www.copia-di-arte.com/a/ wassily-kandinsky/kompositionviii.html. 